\title{
Early Quantification of Hematoma Hounsfield Units on Noncontrast CT in Acute Intraventricular Hemorrhage Predicts Ventricular Clearance after Intraventricular Thrombolysis
}

J. Kornbluth, S. Nekoovaght-Tak, N. Ullman, J.R. Carhuapoma, D.F. Hanley, and W. Ziai

\begin{abstract}
BACKGROUND AND PURPOSE: Thrombolytic efficacy of intraventricular rtPA for acute intraventricular hemorrhage may depend on hematoma composition. We assessed whether hematoma Hounsfield unit quantification informs intraventricular hemorrhage clearance after intraventricular rtPA.
\end{abstract}

MATERIALS AND METHODS: Serial NCCT was performed on 52 patients who received intraventricular rtPA as part of the Clot Lysis Evaluation of Accelerated Resolution of Intraventricular Hemorrhage trial and 12 controls with intraventricular hemorrhage, but no rtPA treatment. A blinded investigator calculated Hounsfield unit values for intraventricular hemorrhage volumes on admission (t0), days 3-4 (t1), and days 6-9 (t2). Controls were matched uniquely to 12 rtPA-treated patients for comparison.

RESULTS: Median intraventricular hemorrhage volume on admission for patients treated with intraventricular rtPA was $31.9 \mathrm{~mL}$ (interquartile range, $34.1 \mathrm{~mL}$ ), and it decreased to $4.9 \mathrm{~mL}$ (interquartile range, $14.5 \mathrm{~mL}$ ) (t2). Mean ( \pm standard error of the mean) Hounsfield unit for intraventricular hemorrhage was 52.1 (0.59) at t0 and decreased significantly to 50.1 (0.63) (t1), and to 45.1 (0.71) (t2). Total intraventricular hemorrhage Hounsfield unit count was significantly correlated with intraventricular hemorrhage volume at all time points ( $\mathrm{t} 0: P=.002 ; \mathrm{t}$ : $P<.001$; t2: $P<.001$ ). On serologic and CSF analysis at t0, only higher CSF protein was positively correlated with intraventricular hemorrhage Hounsfield units $(P=.03)$. In 24 matched patients treated with rtPA and controls, total intraventricular hemorrhage Hounsfield units were significantly lower in patients treated with rtPA at t2 $(P=.02)$. Higher Hounsfield unit quantification of fourth ventricle hematomas independently predicted slower clearance of this ventricle $(95 \% \mathrm{Cl}, 0.02-0.14 ; P=.02)$, along with higher intraventricular hemorrhage volume $(95 \% \mathrm{Cl}, 0.02-0.41 ; P=.03)$ and lower CSF protein levels $(95 \% \mathrm{Cl},-0.003$ to $-0.002 ; P<.001)$.

CONCLUSIONS: Intraventricular hemorrhage Hounsfield unit counts decrease significantly in the acute phase and to a greater extent with intraventricular rtPA treatment. Intraventricular hemorrhage Hounsfield units are correlated significantly with CSF protein and not with serum erythrocyte or platelet concentrations. Hounsfield unit counts may reflect intraventricular hemorrhage clot composition and rtPA sensitivity.

ABBREVIATIONS: CLEAR = Clot Lysis Evaluation of Accelerated Resolution of Intraventricular Hemorrhage; EVD = external ventricular drain; $\mathrm{HU}=\mathrm{Hounsfield} \mathrm{unit;} \mathrm{ICH}=$ intracerebral hemorrhage; $\mathrm{IQR}=$ interquartile range; $\mathrm{IVH}=$ intraventricular hemorrhage; $\mathrm{SEM}=$ standard error of the mean; $\mathrm{t} 0=$ admission; $\mathrm{tl}=$ days $3-4 ; \mathrm{t} 2=$ days $6-9$

ntraventricular hemorrhage (IVH) occurs in approximately $45 \%$ of patients following spontaneous intracerebral hemorrhage $(\mathrm{ICH})$ and is an independent predictor of morbidity and mortali-

Received November 19, 2014; accepted after revision January 15, 2015.

From the Department of Neurology (J.K.), Division of Neurocritical Care, Tufts University School of Medicine, Boston, Massachusetts; and Department of Neurology (J.K., J.R.C., W.Z.), Division of Neurocritical Care, and Department of Neurology (S.N.-T., N.U., J.R.C., D.F.H., W.Z.), Division of Brain Injuries Outcomes, Johns Hopkins University School of Medicine, Baltimore, Maryland.

The CLEAR study was funded by the US Food and Drug Administration, division of Orphan Products Development, and the National Institutes of Health (clinicaltrials. gov identifier: NCT00650858). D.F.H. is funded by CLEAR III 5U01-NS062851-03, and Minimally Invasive Surgery and rtPA for Intracerebral Hemorrhage Evacuation II 5R01-NS046309-07.

Paper previously presented at: Annual Conference of the German Society of Neurocritical Care and Emergency Medicine, January 23-26, 2013; Mannheim, Germany. ty. ${ }^{1-3}$ Previous studies demonstrated that administration of intraventricular rtPA in acute is safe and accelerates clot resolution in experimental models and humans. ${ }^{4,5}$ Evaluation of clot lysis is determined most commonly by serial CT imaging, in which it is assumed that high-attenuation blood represents the actual contour of the solid clot. Less is known about factors that impact the CT attenuation coefficient (in Hounsfield units [HUs]) of intraventricular blood and whether CT attenuation is indicative of clot composition or the success of intraventricular thrombolysis in acute IVH. An analysis of

Please address correspondence to Wendy Ziai, MD, MPH, Johns Hopkins University School of Medicine, Division of Neurocritical Care, Phipps-455, 600 N Wolfe St, Baltimore, MD 21287; e-mail: wziai1@jhmi.edu

\footnotetext{
- Indicates open access to non-subscribers at www.ajnr.org

EN Evidence-Based Medicine Level 2.

http://dx.doi.org/10.3174/ajnr.A4393
} 
factors that impact intraventricular clot lysis rates in patients with large IVH causing obstructive hydrocephalus, who were treated with intraventricular rtPA, found that higher baseline serum plasminogen and lower platelet counts were independently associated with an increase in clot lysis during the first few days. ${ }^{6}$ This finding suggests that intraventricular thrombus composition may impact IVH clot removal.

In acute ischemic stroke, thrombus composition in large arteries can be evaluated on the basis of HUs detected by thinsection NCCT. ${ }^{7} \mathrm{HU}$ counts may aid in predicting recanalization (and resistance to thrombolytics) with intravascular rtPA. ${ }^{7,8} \mathrm{We}$ sought to assess the change in the CT attenuation coefficient of IVH in patients treated with intraventricular rtPA (versus an external ventricular drain [EVD] alone) and to determine radioattenuaton characteristics of intraventricular clot based on $\mathrm{HU}$ measurements that may predict the efficacy of thrombolysis.

\section{MATERIALS AND METHODS Study Design}

This was a post hoc analysis of patients chosen from a hospital ICH registry and from a multicenter trial involving 52 randomized adult patients with obstructive hydrocephalus secondary to IVH and spontaneous ICH volume of $<30 \mathrm{~mL}$ requiring urgent EVD. Twelve cases ( 11 enrolled in the trial plus 1 from the $\mathrm{ICH}$ registry), all treated with intraventricular rtPA, were each matched to 1 unique patient from the ICH registry, all of whom received an EVD within 2 days of IVH onset, but no rtPA (controls).

All except 1 case came from the dose-finding study of The Clot Lysis Evaluation Accelerated Resolution of Intraventricular Hemorrhage trial (CLEAR IVH) $(n=52)$. Patients were either randomized 1:1 $(n=16)$ to receive intraventricular rtPA at doses of 0.3 or $1.0 \mathrm{mg}$ q12 hours (CLEAR A) or $1.0 \mathrm{mg}$ q12 hours or q8 hours $(n=36)$ (CLEAR B). The nonenrolled case received intraventricular rtPA, $1 \mathrm{mg}$ every 12 hours, and was managed in accordance with the study protocol.

Patients and controls were matched according to total IVH volume, ICH volume, and ICH location. IVH and ICH volumes were matched within $10 \mathrm{~mL}$ on the basis of computerized volumetric analysis of the diagnostic CT. Patients receiving placebos from the CLEAR IVH trials could not be used due to lack of electronic CT data for this cohort. This study was approved by the institutional review board of each participating site.

\section{Patient Selection}

Inclusion criteria for the trial required that an EVD had been inserted, a CT scan obtained at least 6 hours later showed no significant new occurrence or increase in size of any hematoma, and the first dose of rtPA could be given within 48 hours of diagnostic head CT. Patients treated with rtPA had an EVD inserted within 24 hours of diagnostic CT in 45 patients and on day 2 in 7. Control patients had an EVD inserted within 24 hours of diagnostic CT in 10 patients and within 48 hours in 2. Exclusion criteria for study patients included the following: traumatic brain injury, posterior fossa parenchymal hemorrhage, parenchymal hemorrhage volume of $>30 \mathrm{~mL}$, suspected intracerebral aneurysm or arteriovenous malformation (excluded by appropriate diagnostic studies), any severe complicating illness, active internal bleeding, current use of heparin (but not antiplatelet agents), coagulopathy with prothrombin time or partial thromboplastin time outside the normal range, platelet count of $<75 \mathrm{IU} / \mathrm{mm}^{3}$, pregnancy, and age younger than 18 years. Controls and 1 patient treated with tPA were not enrolled in the study due to the following: inability to enroll within the allowed time window $(n=3)$, baseline ICH volume of $>30 \mathrm{~mL}(n=2)$, consent declined $(n=1)$, and presentation while the study was not enrolling patients $(n=7)$. Only patients who underwent at least 2 more CT scans after their admission CT ( $\mathrm{t} 0$ ) with at least 1 during days 2-4 (t1) and days 5-9 (t2) after admission were included.

\section{Patient Management}

EVDs were placed by the neurosurgical staff in patients with symptomatic hydrocephalus and a Glasgow Coma Scale score of $<8$. Initial catheters were placed contralateral to side of greatest IVH volume in 47/65 patients (72\%) (37 patients treated with rtPA, 10 controls) and ipsilateral, in 15 patients (23\%). Three patients had simultaneous bilateral EVDs (5\%).

rtPA was delivered after attempting aspiration of at least $4 \mathrm{~mL}$ of CSF. Isovolumetric injection of rtPA was followed by a $2-\mathrm{mL}$ flush of nonbacteriostatic normal saline. After each injection, the EVD was closed for 1 hour to allow time for rtPA-clot interaction and was reopened only if necessary to control medically refractory intracranial pressure elevation. After the clamping period, the EVD was reopened to drain CSF at the gradient set by the treating physician. The first injection of rtPA occurred no sooner than 12 hours but no later than 48 hours after the diagnostic CT and at least 6 hours after EVD placement. rtPA injections continued at the specified interval until clearance of hyperattenuated blood from the third and fourth ventricles was observed on daily head CT or for a maximum of 12 doses in the CLEAR A and B studies. In patients and controls, EVDs were kept open, with a drainage gradient specified by the treating physician $(0-20 \mathrm{~mm} \mathrm{Hg})$ until it was determined appropriate to wean.

\section{Radiologic Assessment}

Neuroimaging was performed on fourth-generation CT scanners at each participating study site. CT scans chosen for analysis were the following: admission day 1 CT ( $\mathrm{t} 0$ ), days 2-4 CT ( $\mathrm{t} 1)$, and days 5-9 CT (t2). CT scans for each interval were chosen as close as possible in time for each case-control pair. Most CT scans consisted of 4- to 5-mm-thick sections through both the skull base and cerebrum. In 10 patients, 19 CT scans consisted of 10-15 sections of 3-mm thickness for the skull base and 10-12 sections of 6-mm thickness for the cerebrum. A single blinded researcher (S.N.-T.) manually mapped out ROIs around the intraventricular and parenchymal hematomas and around the contour of each ventricle on continuous images from representative CT scans by using an open-source DICOM viewer software program for MAC (OsiriX Imaging Software, Version 4.1; http://www.osirix-viewer.com) (Fig 1). A semiautomated thresholdbased approach with a range of $40-80 \mathrm{HU}$ was used to initially identify regions and then was manually adjusted to obtain the best delineation of blood clot and avoid artifacts introduced by higher attenuation CSF. The software adjusts for changes in section thickness and thereby corrects for different CT techniques across centers. 


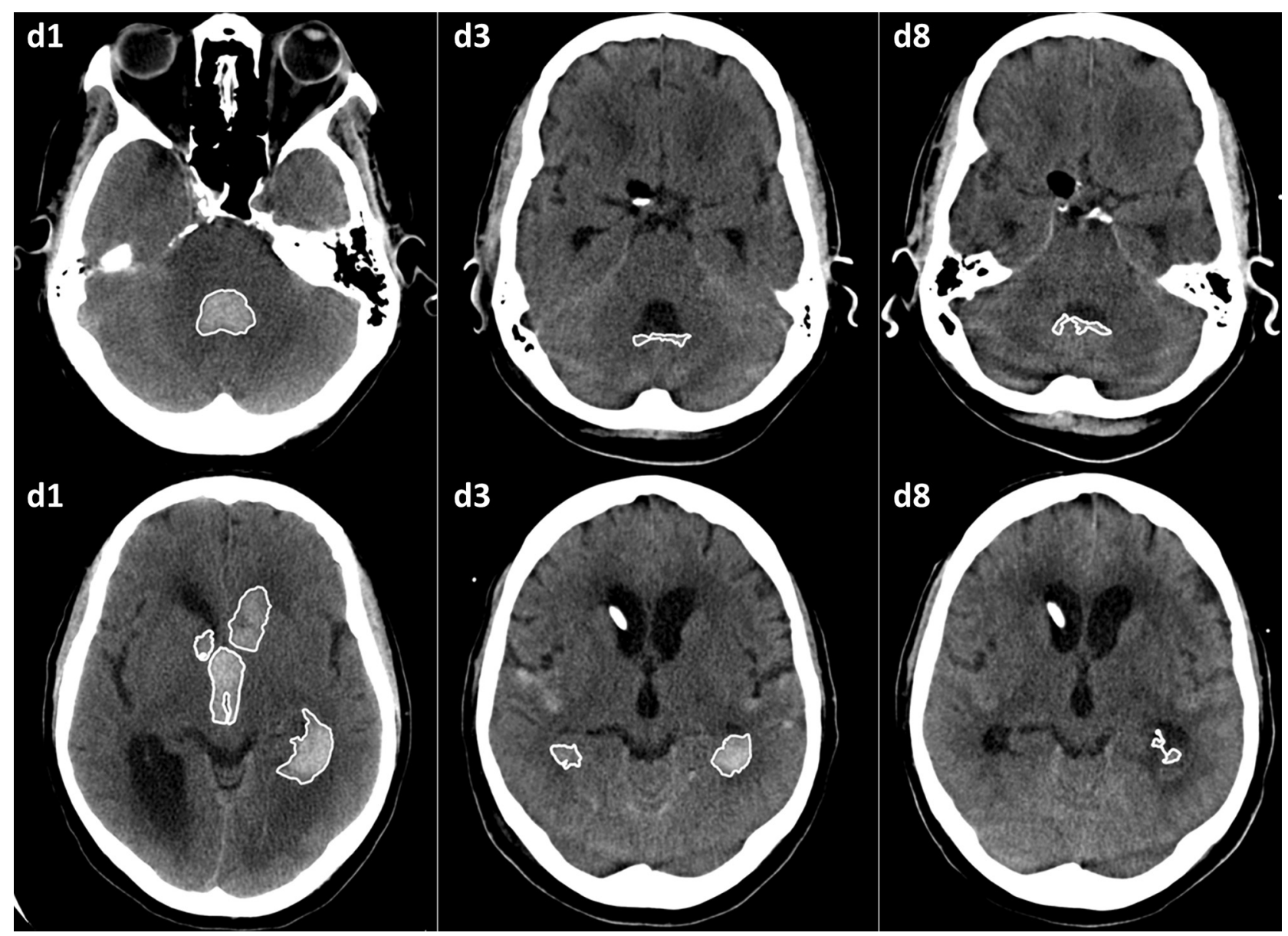

FIG 1. ROI mapping of IVH in a typical patient on days 1, 3, and 8 .

The volumes and mean HU counts of the IVH and ICH clots and of the ventricular fluid not containing acute blood were calculated with this semiautomatic procedure. The HU values were obtained for each ROI by averaging all voxels within the ROI. IVH ROIs were analyzed as total IVH values and by component ventricle location (right and left lateral, third and fourth ventricles).

\section{Data Analysis}

We collected demographic and baseline characteristics, including the following serologic and CSF data at initial presentation or at EVD insertion: hematocrit, platelet count, prothrombin time, partial thromboplastin time, plasma fibrinogen level, CSF red blood cell and white blood cell counts, CSF protein level, and CSF glucose level. For univariate analysis, we correlated mean $\mathrm{HU}$ counts from all patients in the trial $(N=52)$ with IVH and ICH volumes, serologic and CSF data at initial presentation, sex, number of and total rtPA doses, side of the EVD relative to predominant IVH volume, and ventricle component across time points by using Spearman correlation tests and Student $t$ tests as appropriate. In 24 matched patients, demographic variables, baseline characteristics, IVH and ICH volumes, HUs, and serologic and CSF data were compared between patients treated with rtPA and controls by using the Student $t$ test and $\chi^{2}$ or the Fisher exact test as appropriate. The Wilcoxon signed rank test was used to compare variables with non-normal distributions. Data are presented as mean \pm standard error of the mean (SEM) or median (interquar- tile range $[\mathrm{IQR}]$ ) unless otherwise indicated. Statistical analysis was performed with STATA 11.0 (StataCorp, College Station, Texas). A value of $P<.05$ was significant.

\section{RESULTS}

\section{Patients Treated with rtPA}

Patient demographics and radiographic findings for patients in the trial are outlined in Table 1. IVH volume decreased significantly at both $\mathrm{t} 1$ and $\mathrm{t} 2$ relative to $\mathrm{t} 0$ in patients treated with rtPA $(N=52)(P<.001$ for both $)$. Progression of HU counts with time (Fig 2) showed that total ventricular HU counts decreased significantly from $52.14 \pm 0.59(\mathrm{t} 0)$ to $50.11 \pm 0.63$ (t1) $(P=.002)$ to $45.05 \pm 0.71(\mathrm{t} 2)(P<.001 ; \mathrm{t} 2$ versus $\mathrm{t} 0)$. The decrease in HU counts was significant for all ventricular compartments when analyzed individually. IVH volume was significantly correlated with $\mathrm{HU}$ counts at all time points: t0 (Spearman $\rho=0.41, P=.002)$; t1 $(\rho=0.70, P<.001)$; and $\mathrm{t} 2$ $(\rho=0.64, P<.001)$.

Time from EVD placement to resolution of casted third or fourth ventricle clot occurred at a median of 2.7 days (range, $0.29-8.46$ days) and 2.2 days (range, $0.23-5.78$ days), respectively, and was positively correlated with third or fourth ventricle HU counts at $\mathrm{t} 0$, respectively (third ventricle: $\rho=0.30, P=.04$; fourth ventricle: $\rho=$ $0.37, P=.02$ ); higher HU correlated with longer time to clot resolution. The third ventricle failed to clear in 3 patients from to to $t 2$. Factors at t0 independently associated with slower clearance of the 
Table 1: Clinical and radiologic characteristics of patients treated with rtPA $(N=52)$

\begin{tabular}{|c|c|c|}
\hline & rtPA-Treated $(N=52)$ & $\begin{array}{c}\text { P Value (Where } \\
\text { Appropriate) }\end{array}$ \\
\hline \multicolumn{3}{|l|}{ Clinical characteristics } \\
\hline Age $(y r)($ mean \pm SEM) & $55.6 \pm 1.4$ & \\
\hline Male/female & $34: 18$ & \\
\hline Admission GCS (median) (IQR) & $8.5(9.0)$ & \\
\hline \multicolumn{3}{|l|}{ Radiographic characteristics } \\
\hline \multicolumn{3}{|l|}{$\mathrm{ICH}$ location (\%) } \\
\hline Basal ganglia & $8(15.4)$ & \\
\hline Caudate & $2(3.8)$ & \\
\hline Thalamus & $25(48.1)$ & \\
\hline Lobar & $6(11.5)$ & \\
\hline Primary IVH & $11(21.2)$ & \\
\hline Admission Graeb score ${ }^{21}$ (median) (IQR) & $7(3)$ & \\
\hline \multicolumn{3}{|l|}{ Total IVH volume $\left(\mathrm{cm}^{3}\right)$ (median) (IQR) } \\
\hline to & $31.94(34.1)$ & \\
\hline $\mathrm{tl}$ & $12.84(26.23)$ & .001 (tl vs t0) $^{\mathrm{a}}$ \\
\hline t2 & $4.86(14.49)$ & .001 (t2 vs t0) ${ }^{\mathrm{a}}$ \\
\hline \multicolumn{3}{|l|}{ Total IVH HU counts (mean \pm SEM) } \\
\hline to & $52.14 \pm 0.59$ & \\
\hline tl & $50.11 \pm 0.63$ & .002 (tl vs t0) $^{\mathrm{a}}$ \\
\hline t2 & $45.05 \pm 0.71$ & .001 (t2 vs t0) $)^{\mathrm{a}}$ \\
\hline \multicolumn{3}{|l|}{ Total CSF HU counts (mean \pm SEM) } \\
\hline to & $12.37 \pm 0.37$ & \\
\hline $\mathrm{tl}$ & $11.77 \pm 0.37$ & .18 (tl vs t0) \\
\hline t2 & $11.30 \pm 0.33$ & .01 (t2 vs t0) $^{\mathrm{a}}$ \\
\hline \multicolumn{3}{|c|}{ Hematoma (ICH) volume $\left(\mathrm{cm}^{3}\right)$ (median) (IQR) } \\
\hline to & $7.0(10.11)$ & \\
\hline t1 & $5.35(9.39)$ & .001 (tl vs t0) $^{\mathrm{a}}$ \\
\hline t2 & $5.04(8.06)$ & $.001\left(\mathrm{t} 2\right.$ vs to) ${ }^{\mathrm{a}}$ \\
\hline \multicolumn{3}{|l|}{ Hematoma (ICH) HU counts (mean \pm SEM) } \\
\hline to & $55.06 \pm 0.82$ & \\
\hline tl & $54.78 \pm 0.86$ & .74 (tl vs t0) \\
\hline t2 & $48.42 \pm 0.84$ & $.001\left(\mathrm{t} 2\right.$ vs t0) ${ }^{\mathrm{a}}$ \\
\hline \multicolumn{3}{|l|}{ Change in IVH volume $\left(\mathrm{cm}^{3}\right)$ (median) (IQR) } \\
\hline Days 2-4 (tl-t0) & $-15.36(18.13)$ & $.001^{\mathrm{a}}$ \\
\hline Days 5-9 (t2-t0) & $-17.72(21.84)$ & $.001^{\mathrm{a}}$ \\
\hline \multicolumn{3}{|l|}{ Change in $\mathrm{ICH}$ volume $\left(\mathrm{cm}^{3}\right)$ (median) (IQR) } \\
\hline Days 2-4 (tl-t0) & $-1.59(3.22)$ & $.001^{\mathrm{a}}$ \\
\hline Days 5-9 (t2-t0) & $-1.66(3.8)$ & $.001^{\mathrm{a}}$ \\
\hline \multicolumn{3}{|l|}{ Change in IVH HU counts (mean \pm SEM) } \\
\hline Days 2-4 (tl-t0) & $-2.03 \pm 0.62$ & $.002^{\mathrm{a}}$ \\
\hline Days 5-9 (t2-t0) & $-6.89 \pm 0.74$ & $.001^{\mathrm{a}}$ \\
\hline \multicolumn{3}{|l|}{ Change in ICH HU counts (mean \pm SEM) } \\
\hline Days 2-4 (t1-t0) & $-0.28 \pm 0.86$ & .74 \\
\hline Days 5-9 (t2-t0) & $-6.65 \pm 1.12$ & $.001^{\mathrm{a}}$ \\
\hline
\end{tabular}

Note:-GCS indicates Glasgow Coma Scale.

a Significant.

fourth ventricle were higher fourth ventricle HU counts (95\% CI, $0.02-0.14 ; P=.02)$, larger fourth ventricle IVH volume $(95 \% \mathrm{CI}$, $0.02-0.41 ; P=.03$ ), and lower CSF protein levels (95\% CI, -0.003 to $-0.002 ; P<.001)$. Factors at $t 0$ independently associated with slower clearance of the third ventricle were larger third ventricle IVH volume (95\% CI, 0.04-0.57; $P=.03$ ) and lower CSF protein levels (95\% CI, -0.004 to $-0.001 ; P=.007)$, but not third ventricle HU counts $(P=.35)$. Lower initial HU counts were significantly correlated with greater change in IVH volume from admission to tl ( $\rho=$ $-0.28, P=.048)$, but not at $\mathrm{t} 2(P=.11)$. After adjustment for admission IVH volume, however, initial HU counts were not significantly associated with the change in IVH volume. The decrease in mean IVH HU counts for all ventricles with time did not correlate with the number of doses of IVR rtPA at t1 $(\rho=0.12, P=.43)$ or $\mathrm{t} 2$ $(\rho=-0.23, P=.11)$. There was no correlation between the side of
EVD placement and the ipsilateral decrease in HU over the duration of the investigation $(P=.60)$.

\section{Matched Pairs}

Patients and controls $(n=24)$ were well-matched in baseline ICH and IVH volume (Table 2). t1 and t2 CT scans were performed at a mean of $3.2 \pm 0.88$ days and $6.2 \pm 1.4$ days after admission, which was not different between groups $(P=.59[\mathrm{t} 1], P=.10$ [t2]). IVH volume decreased significantly faster at both $\mathrm{t} 1$ and $\mathrm{t} 2$ relative to $\mathrm{t} 0$ in patients treated with rtPA compared with controls. The mean IVH HU count in the rtPA group was 52.71 (1.18) at t0 and decreased significantly to $49.01(0.98)$ at $\mathrm{t} 1$, and to 45.05 (1.24) at $\mathrm{t} 2$. IVH HU counts in controls were not significantly different from those in patients treated with rtPA at $\mathrm{t} 0$ and $\mathrm{t} 1$ but were significantly higher at t2 (49.48 [1.33], $P=.02$ ) (Fig 3).

\section{Correlation with Serologic and CSF Data}

There was no significant correlation between admission CT total IVH HU count and the admission values of serum platelet count, prothrombin time, partial thromboplastin time, fibrinogen level, hemoglobin level, and hematocrit level or white blood cell count. Admission ICH HU count showed a trend correlation with serum hematocrit $(\rho=0.26, P=.06)$. Higher CSF protein (median, $112 \mathrm{~g} / \mathrm{dL}$; range, $2.11-986 \mathrm{~g} / \mathrm{dL}$ ) was significantly positively correlated with IVH HU ( $\rho=$ $0.42, P=.03)$. CSF glucose levels and white blood cell counts were not correlated with IVH HU counts. There was a weakly positive correlation between CSF red blood cell count and IVH HU $(\rho=$

$0.34, P=.07)$. There were no positive correlations between patient serologic markers and HU change from to to $t 2$.

HU levels of CSF not containing high-attenuation blood (ie, CSF with $\mathrm{HU}<40$ ) decreased nonsignificantly from $\mathrm{t} 0$ to $\mathrm{t} 2$. No measured CSF components were correlated with these low-attenuation CSF HU counts.

\section{Clinical Outcomes}

Adjudicated safety events in the dose-finding studies of the CLEAR IVH trials on which this study is based totaled $3 / 52$ (5.8\%) symptomatic hemorrhages at any time up to 72 hours after the last dose of rtPA, 1 (2.0\%) case of bacterial ventriculitis, and $8(17 \%)$ deaths at 30 days. One patient required a ventriculoperitoneal shunt $(2 \%)$. 




FIG 2. Change in total IVH HU counts with time in patients treated with rtPA.

\section{DISCUSSION}

We found that intraventricular clot HU counts decreased during the first week after IVH, both in controls and patients treated with rtPA, though with significantly greater change in the treated group. CSF has a HU number of $0-24$ (depending on protein content), and the range for whole blood is linearly related to hematocrit level. ${ }^{9,10}$ Compared with unclotted whole blood (HU count of 56 with hematocrit level of $45 \%$ ), when whole blood coagulates in vitro, the clot retracts and HU count rises to, for example, 75 with hematocrit level elevation to $80 \% .{ }^{11}$ It is believed that the high-attenuation intraventricular cast seen on CT after spontaneous IVH is solid clot, which has been confirmed by postmortem examination in a dog model. ${ }^{12}$ The HU values observed on admission CT scans in this study were similar to those in unclotted whole blood. Despite "retraction" of parenchymal clots, ICH HU counts decreased during the observation period as did IVH HU counts. This finding likely indicates that most retraction had already occurred within the first few hours of bleeding and that other factors (ie, fibrinolytic activity and possibly absorption) were occurring at the $\mathrm{t} 1$ and $\mathrm{t} 2 \mathrm{CT}$ times. Lower attenuation of ventricular clots with time likely reflects both suspension of the clot in CSF and fibrinolysis causing solid clot to become liquid whole blood at least at the surface, which forms a low-hematocrit, low-attenuation blood-CSF mixture. In vitro, fibrinolysis of a solid clot decreases attenuation by 15-20 HU, blurring the margin between solid and liquid blood. ${ }^{13}$ In CSF where HU counts changed relatively little during the period of observation, red blood cells likely fall away from the solid clot and are removed by the steady flow of CSF, which keeps attenuation values low and maintains a clear interface between clot and CSF. The greater decrease in HU counts in patients treated with rtPA compared with controls in Fig 3 likely reflects a combination of increased lytic activity and perhaps improved CSF flow, especially at $\mathrm{t} 2$ when most patients treated with rtPA had opened the lower ventricular system.

Two factors were significantly correlated with higher admission ventricular clot HU counts: higher IVH volume and higher expelled CSF protein. ICH volume was not significantly correlated with $\mathrm{ICH} H \mathrm{HU}$ except at $\mathrm{t} 2$. The absolute changes in $\mathrm{ICH}$ and IVH HU counts from to to $\mathrm{t} 2$ in the whole rtPA-treated group were similar, but with much smaller change in ICH volume. This result might mean that decreased attenuation of IVH associated with clot dissolution is not influenced by rtPA. However, in the matched-pair data, changes in IVH volume and IVH HU counts were significantly greater in the patients treated with rtPA versus controls, whereas the decrease in ICH HU counts was not significantly different at $\mathrm{T} 2$ between groups and decreased by less than $\mathrm{HU}$ in the ventricles. These observations suggest that fibrinolytic activity is associated with $\mathrm{HU}$ counts. Whether intraventricular rtPA may influence fibrinolytic activity of parenchymal hematomas is not clear from this analysis.

Higher CSF protein was significantly correlated with total ventricular clot HUs; this finding is not surprising given its positive influence on CSF attenuation. Earlier reports with first-generation CT scanners described a linear relationship between CSF protein and the CT attenuation coefficient, though with only a small variation in HUs across the spectrum from normal to pathologic values, consistent with our data. ${ }^{10}$ Therefore we adjusted for both IVH volume and CSF protein to assess whether HU counts predict time to clearance of the third and fourth ventricles on CT, a commonly used end point of intraventricular fibrinolysis that determines the end of dosing. We found that higher HU quantification of the fourth, but not the third, ventricle hematoma was significantly associated with slower clearance of this ventricle in the setting of intraventricular rtPA administration after adjusting for compartmental IVH volume and CSF protein.

Intraventricular clots contain varying amounts of fibrin, platelets, and red blood cells. Clots with more red blood cells would be expected to have a higher concentration of hemoglobin and therefore HU counts compared with those with more fibrin and platelets. Prior models of intra-arterial clot have shown that more radioattenuated clots may contain proportionately more red blood cells than platelets and may be more amenable to thrombolysis with rtPA. ${ }^{14}$ We previously found that a lower serum platelet count was associated with faster clearance of ventricular clot. ${ }^{6}$ These results appear to be inconsistent with those in this study, which found no relationship between admission IVH HU counts and serum hematocrit or platelet count and only a weak positive correlation with CSF red blood cell count, findings suggesting that radioattenuaton characteristics of intravascular and intraventricular clots reflect different properties. HU counts of ventricular clots may also reflect attenuation of the fibrin mesh network. Dissolution of thrombus depends on diffusion and permeation of thrombolytic into the clot, which may be impaired by a tighter clot structure associated with a higher attenuation coefficient, independent of clot size or CSF protein.

Faster clearance of the lower ventricular system (both third and fourth ventricles) was independently associated with higher CSF protein at $\mathrm{t} 0$, suggesting that higher protein levels may be associated with greater CSF fibrinolytic activity. Approximately $80 \%$ of CSF protein is serum-derived, and $20 \%$ is produced intrathecally. ${ }^{15}$ However, bleeding into the ventricles contributes significantly to initial CSF protein levels, raising the possibility that fibrinolytic enzymes such as serum plasminogen are contributing to this effect. Higher CSF protein levels may also be the result of greater clot dissolution and not a causative factor.

This study was limited in several ways. The sample size was AJNR Am J Neuroradiol 36:1609-15 Sep 2015 www.ajnr.org 1613 
Table 2: Clinical and radiologic data for matched pairs

\begin{tabular}{|c|c|c|c|}
\hline & $\begin{array}{l}\text { rtPA-Treated } \\
(N=12)\end{array}$ & $\begin{array}{l}\text { Control } \\
(N=12)\end{array}$ & $P$ Value \\
\hline \multicolumn{4}{|l|}{ Clinical characteristics } \\
\hline Age $(y r)($ mean \pm SEM) & $52.8 \pm 2.0$ & $57.5 \pm 1.9$ & .21 \\
\hline Sex, male/female & 11:1 & $7: 5$ & .06 \\
\hline Admission GCS (median) (IQR) & $8.5(6)$ & $5.5(4.5)$ & .06 \\
\hline \multicolumn{4}{|l|}{ Radiographic characteristics } \\
\hline \multicolumn{4}{|l|}{$\mathrm{ICH}$ location } \\
\hline Basal ganglia & 2 & 3 & .57 \\
\hline Caudate & 3 & 1 & \\
\hline Thalamus & 7 & 8 & \\
\hline Admission Graeb score (median) (IQR) & $8(1.5)$ & $8(4)$ & .19 \\
\hline \multicolumn{4}{|l|}{ Total IVH volume $\left(\mathrm{cm}^{3}\right)(\text { mean } \pm \text { SEM) })^{12}$} \\
\hline to & $26.0 \pm 2.51$ & $26.34 \pm 3.24$ & .87 \\
\hline $\mathrm{tl}$ & $13.56 \pm 2.70$ & $25.20 \pm 3.73$ & $.005^{a}$ \\
\hline t2 & $6.26 \pm 1.36$ & $18.63 \pm 2.83$ & $.002^{\mathrm{a}}$ \\
\hline \multicolumn{4}{|c|}{ Total ventricular volume $\left(\mathrm{cm}^{3}\right)($ mean $\pm \mathrm{SEM})$} \\
\hline to & $69.13 \pm 5.85$ & $84.11 \pm 8.40$ & .18 \\
\hline $\mathrm{tl}$ & $34.78 \pm 4.96$ & $56.57 \pm 5.70$ & $.01^{\mathrm{a}}$ \\
\hline t2 & $24.80 \pm 2.67$ & $57.57 \pm 10.32$ & $.01^{\mathrm{a}}$ \\
\hline \multicolumn{4}{|c|}{ Hematoma $(\mathrm{ICH})$ volume $\left(\mathrm{cm}^{3}\right)($ mean $\pm \mathrm{SEM})$} \\
\hline to & $12.93 \pm 3.59$ & $14.29 \pm 3.23$ & .39 \\
\hline tl & $14.21 \pm 3.93$ & $14.92 \pm 2.97$ & .74 \\
\hline t2 & $11.17 \pm 3.64$ & $13.76 \pm 3.19$ & .29 \\
\hline \multicolumn{4}{|l|}{ IVH HU counts (mean \pm SEM) } \\
\hline to & $52.71 \pm 1.18$ & $52.05 \pm 0.96$ & .70 \\
\hline $\mathrm{t} 1$ & $49.01 \pm 0.98$ & $50.42 \pm 1.55$ & .35 \\
\hline t2 & $45.05 \pm 1.24$ & $49.48 \pm 1.33$ & .02 \\
\hline \multicolumn{4}{|l|}{ ICH HU counts (mean \pm SEM) } \\
\hline to & $56.24 \pm 1.84$ & $54.12 \pm 1.17$ & .25 \\
\hline tl & $55.79 \pm 1.08$ & $52.80 \pm 1.08$ & $.04^{\mathrm{a}}$ \\
\hline t2 & $52.06 \pm 1.28$ & $52.56 \pm 1.10$ & .77 \\
\hline \multicolumn{4}{|l|}{ Radiologic outcomes } \\
\hline \multicolumn{4}{|l|}{ Change in IVH volume $\left(\mathrm{cm}^{3}\right)$ (median) (IQR) } \\
\hline Days $2-4$ (tl-t0) & $-10.88(12.84)$ & $-1.24(2.78)$ & $.002^{\mathrm{a}}$ \\
\hline Days 5-9 (t2-t0) & $-18.65(14.88)$ & $-6.85(6.36)$ & $.002^{\mathrm{a}}$ \\
\hline \multicolumn{4}{|l|}{ Change in $\mathrm{ICH}$ volume $\left(\mathrm{cm}^{3}\right)$ (median) (IQR) } \\
\hline Days 2-4 (tl-t0) & $0.24(1.91)$ & $-.06(2.99)$ & .88 \\
\hline Days 5-9 (t2-t0) & $-1.98(3.25)$ & $-1.15(2.33)$ & .27 \\
\hline \multicolumn{4}{|l|}{ Change in IVH HU counts (mean \pm SEM) } \\
\hline Days $2-4$ (tl-t0) & $-3.70 \pm 1.44$ & $-1.63 \pm 1.50$ & .07 \\
\hline Days 5-9 (t2-t0) & $-7.66 \pm 1.87$ & $-2.58 \pm 1.23$ & $.02^{\mathrm{a}}$ \\
\hline \multicolumn{4}{|l|}{ Change in ICH HU counts (mean \pm SEM) } \\
\hline Days $2-4(\mathrm{t}-\mathrm{t}-\mathrm{0})$ & $-0.59 \pm 1.55$ & $-1.31 \pm 1.51$ & .63 \\
\hline Days 5-9 (t2-t0) & $-4.18 \pm 2.23$ & $-1.55 \pm 1.39$ & .25 \\
\hline
\end{tabular}

Note:-GCS indicates Glasgow Coma Scale.

a Significant.

relatively small, but all patients were treated with the same protocolized approach to imaging and clinical management. We tried to minimize bias with the matched case-control design for comparison of EVD-only versus patients treated with rtPA. Cases and controls were carefully matched on IVH and ICH volumes and $\mathrm{ICH}$ location to minimize differences between groups. This matching resulted in a limited pool of patients. Determining the exact margin of the clot-CSF interface is a potential source of error, though an $\mathrm{HU}$ threshold of 40 was applied similarly by using a semiautomated approach and all CT scans were evaluated and mapped by a single blinded researcher. Associations between HU quantification and change in IVH volumes reflect the most accurate assessment methods available but may have been affected by disparities in sampling, patient age, and time of EVD placement. Numerous factors have been shown to influence clearance rates of intraventricular blood after rtPA administration, including the location of the external ventricular drain, ${ }^{16}$ bilateral-versus-single EVD, ${ }^{17}$ the location of intraventricular blood, dose of thrombolytic, ${ }^{18}$ and serum and CSF components. Our investigation examined the radiographic characteristics that complement these data.

Finally, it remains to be determined whether changing intraventricular clot volume and characteristics translates into positive outcomes. Several meta-analyses (on observational studies and small randomized trials) all suggested that intraventricular rtPA may be an effective strategy for reducing mortality and improving functional outcome, with the potential for decreasing permanent shunt rates without significant increase in complications. ${ }^{19-21}$ Adverse events in this study were lower than the reported rates and support data showing that intraventricular fibrinolysis does not significantly increase the risk of rehemorrhage or infection. ${ }^{21}$ The soonto-be-completed Phase III multinational, randomized controlled trial (Clot Lysis Evaluation of Accelerated Resolution of Intraventricular Hemorrhage [CLEARIII]) of 500 patients with primary or secondary spontaneous IVH randomized to intraventricular fibrinolysis with rtPA or placebo should provide the highest quality evidence on the benefits and complications of this treatment. ${ }^{22}$

\section{CONCLUSIONS}

Attenuation of intraventricular hemorrhage is significantly associated with CSF protein levels and may reflect properties of IVH clot structure yet to be defined. A significantly greater reduction in IVH attenuation during the acute phase occurs with intraventricular rtPA administration compared with EVD alone. HU measurement on NCCT may be useful in predicting the effectiveness of intraventricular rtPA, especially in the fourth ventricle.

Disclosures: Joshua Kornbluth—UNRELATED: Grants/Grants Pending: Pfizer, ${ }^{*}$ Comments: grant support for an unrelated project. Daniel F. Hanley—RELATED: National Institutes of Health/National Institute of Neurological Disorders and Stroke, ${ }^{*}$ Comments: CLEAR III and Minimally Invasive Surgery and rtPA for Intracerebral Hemorrhage Evacuation II and III clinical trials; Provision of Writing Assistance, Medicines, Equipment, or Administrative Support: Genentech, ${ }^{*}$ Comments: supply rtPA drug for clinical trials CLEAR and Minimally Invasive Surgery and rtPA for Intracerebral Hemorrhage Evacuation; UNRELATED: Consultancy: BrainScope; Expert Testimony: expert witness on brain hemorrhage; Payment for Lectures (including service on Speakers Bureaus): honoraria from various universities. Natalie Ullman-RELATED: Grant: The CLEAR study was funded by the US Food and Drug Administration, division of Orphan Products Development, and National Institutes of Health (clinicaltrials.gov identifier: NCT00650858)*; additional funding by CLEAR III 5U01NS062851-03, and Minimally Invasive Surgery and rtPA for Intracerebral Hemorrhage 


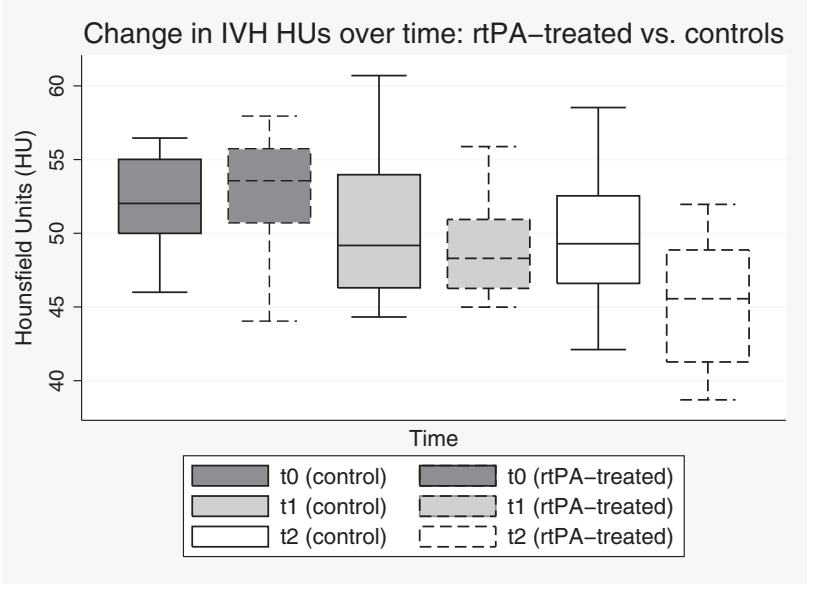

FIG 3. Change in IVH HU with time in patients treated with rtPA versus controls $(n=24)$.

Evacuation II 5R01-NS046309-07. * Wendy Ziai-RELATED: Grant: National Institutes of Health/National Institute of Neurological Disorders and Stroke 5U01, ${ }^{\star}$ Comments: receive funding as a site investigator for this study. ${ }^{*}$ Money paid to the institution.

\section{REFERENCES}

1. Diringer MN, Edwards DF, Zazulia AR. Hydrocephalus: a previously unrecognized predictor of poor outcome from supratentorial intracerebral hemorrhage. Stroke 1998;29:1352-57 CrossRef Medline

2. Tuhrim S, Dambrosia JM, Price TR, et al. Prediction of intracerebral hemorrhage survival. Ann Neurol 1988;24:258-63 CrossRef Medline

3. Steiner T, Diringer MN, Schneider D, et al. Dynamics of intraventricular hemorrhage in patients with spontaneous intracerebral hemorrhage: risk factors, clinical impact, and effect of hemostatic therapy with recombinant activated factor VII. Neurosurgery 2006; 59:767-73; discussion 773-74 CrossRef Medline

4. Naff N, Williams M, Keyl PM, et al. Low-dose recombinant tissuetype plasminogen activator enhances clot resolution in brain hemorrhage: the intraventricular hemorrhage thrombolysis trial. Stroke 2011;42:3009-16 CrossRef Medline

5. Naff NJ, Williams MA, Rigamonti D, et al. Blood clot resolution in human cerebrospinal fluid: evidence of first-order kinetics. Neurosurgery 2001;49:614-19; discussion 619-21 CrossRef Medline

6. Ziai WC, Muschelli J, Thompson CB, et al. Factors affecting clot lysis rates in patients with spontaneous intraventricular hemorrhage. Stroke 2012;43:1234-39 CrossRef Medline

7. Puig J, Pedraza S, Demchuk A, et al. Quantification of thrombus Hounsfield units on noncontrast $\mathrm{CT}$ predicts stroke subtype and early recanalization after intravenous recombinant tissue plasminogen activator. AJNR Am J Neuroradiol 2012;33:90-96 CrossRef Medline

8. Kirchhof $\mathrm{K}$, Welzel T, Mecke C, et al. Differentiation of white, mixed, and red thrombi: value of CT in estimation of the prognosis of thrombolysis phantom study. Radiology 2003;228:126-30 CrossRef Medline

9. New PF, Aronow S. Attenuation measurements of whole blood and blood fractions in computed tomography. Radiology 1976;121: 635-40 CrossRef Medline

10. Norman D, Price D, Boyd D, et al. Quantitative aspects of computed tomography of the blood and cerebrospinal fluid. Radiology 1977; 123:335-38 CrossRef Medline

11. Scott WR, New PF, Davis KR, et al. Computerized axial tomography of intracerebral and intraventricular hemorrhage. Radiology 1974; 112:73-80 CrossRef Medline

12. Pang D, Sclabassi RJ, Horton JA. Lysis of intraventricular blood clot with urokinase in a canine model, part 3: effects of intraventricular urokinase on clot lysis and posthemorrhagic hydrocephalus. $\mathrm{Neu}$ rosurgery 1986;19:553-72 CrossRef Medline

13. Bergström M, Ericson K, Levander B, et al. Variation with time of the attenuation values of intracranial hematomas. J Comput Assist Tomogr 1977;1:57-63 CrossRef Medline

14. Kim EY, Heo JH, Lee SK, et al. Prediction of thrombolytic efficacy in acute ischemic stroke using thin-section noncontrast CT. Neurology 2006;67:1846-48 CrossRef Medline

15. Watson MA, Scott MG. Clinical utility of biochemical analysis of cerebrospinal fluid. Clin Chem 1995;41:343-60 Medline

16. Jaffe J, Melnychuk E, Muschelli J, et al. Ventricular catheter location and the clearance of intraventricular hemorrhage. Neurosurgery 2012;70:1258-63; discussion 1263-64 CrossRef Medline

17. Hinson HE, Melnychuk E, Muschelli J, et al. Drainage efficiency with dual versus single catheters in severe intraventricular hemorrhage. Neurocrit Care 2012;16:399-405 CrossRef Medline

18. Webb AJ, Ullman NL, Mann S, et al. Resolution of intraventricular hemorrhage varies by ventricular region and dose of intraventricular thrombolytic: the Clot Lysis: Evaluating Accelerated Resolution of IVH (CLEAR IVH) program. Stroke 2012;43:1666-68 CrossRef Medline

19. Staykov D, Bardutzky J, Huttner HB, et al. Intraventricular fibrinolysis for intracerebral hemorrhage with severe ventricular involvement. Neurocrit Care 2011;15:194-209 CrossRef Medline

20. Gaberel T, Magheru C, Parienti JJ, et al. Intraventricular fibrinolysis versus external ventricular drainage alone in intraventricular hemorrhage: a meta-analysis. Stroke 2011;42:2776-81 CrossRef Medline

21. Khan NR, Tsivgoulis G, Lee SL, et al. Fibrinolysis for intraventricular hemorrhage: an updated meta-analysis and systematic review of the literature. Stroke 2014;45:2662-69 CrossRef Medline

22. Ziai WC, Tuhrim S, Lane K, et al; CLEAR III Investigators. A multicenter, randomized, double-blinded, placebo-controlled phase III study of Clot Lysis Evaluation of Accelerated Resolution of Intraventricular Hemorrhage (CLEAR III). Int J Stroke 2014;9:536-42 CrossRef Medline

23. Graeb DA, Robertson WD, Lapointe JS, et al. Computed tomographic diagnosis of intraventricular hemorrhage: etiology and prognosis. Radiology 1982;143:91-96 CrossRef Medline 